\title{
Tarih Öğretiminde Bilgisayar Destekli Öğretimin Akademik Başarıya, Öğrenilenlerin Kalıcılığına ve Bilgisayara Karşı Tutuma Etkisi
}

\author{
Mustafa YAĞCl, Yrd. Doç. Dr., Ahi Evran Üniversitesi Eğitim Fakültesi, mustafayagci06@gmail.com
}

Öz: Bu çalışmanın amacı, ortaöğretim 10. Sınıf Tarih dersini içeren bilgisayar destekli öğretimin, öğrencilerin akademik başarılarına, öğrenilenlerin kalıcılığına ve bilgisayara yönelik tutuma etkisini ortaya koymaktır. Araştırmanın çalışma grubunu 2015-2016 eğitim-öğretim yılı birinci döneminde, özel bir ortaöğretim okulunda öğrenim gören toplam 60 (28 deney grubu, 32 kontrol grubu) öğrenci oluşturmaktadır. Araştırmada öntest sontest kontrol gruplu yarı deneysel desen kullanılmıştır. Ortaöğretim 10. sınıflardan dört farklı şubeden, iki şube deney grubu, diğer iki şube ise kontrol grubu olarak belirlenmiştir. Deney grubuna Tarih dersi bilgisayar destekli öğretim yöntemi ile 10 hafta süreyle anlatılmıştır. Kontrol grubuna ise aynı konular geleneksel metotlar ile anlatılmıştır. Veri toplama aracı olarak akademik başarı testi, açık uçlu sorulardan oluşan kalıcılık testi ve bilgisayara yönelik tutum ölçeği kullanılmıştır. Sonuç olarak, deney ve kontrol gruplarının sontest başarı puanları arasında bilgisayar destekli öğretimin yapıldığı deney grubu lehine anlamlı farklılık bulunmuştur. Öte yandan, öğrencilerin bilgisayara yönelik tutumlarında anlamlı farklılık gözlenmemiştir.

Anahtar Sözcükler: bilgisayar destekli öğretim, akademik başarı, bilgisayara yönelik tutum, kalıcı öğrenme, tarih öğretimi

\section{The Effect of Computer-Assisted Instruction on Achievement, Retention and Attitudes toward Computer in History Teaching}

\begin{abstract}
The purpose of this study was to examine the effects of computer supported historyteaching method on 10th grade students' achievement retention and their attitudes toward computers. The sample of this study included 60 (28 experimental, 32 control) students in a private school in the 2015-2016 academic year. In this study, pretest-posttest quasi-experimental research design was used. Among 10th grade students, two different sections were selected as experimental group ant other two for the control group. The experimental group was exposed to computer supported history lessons for 10 weeks. In the control group, traditional teaching methods were used to teach the same content. To collect data, an achievement test, a retention test that included open-ended questions, attitudes toward computers scale were used. The results revealed that post test scores of students in the experimental group was significantly higher than those in the control group and there were differences in students' attitudes toward computers favoring the experimental group.
\end{abstract}

Key Words: computer assisted instruction, achievement, attitudes toward computer, retention, history-teaching 


\section{GíRiş}

Bilimsel ve teknolojik alandaki gelişmeler, sanayiden sonra eğitimi de etkilemiş ve buna bağlı olarak bilişim teknolojileri, eğitim sistemlerine entegre edilmeye çalışımıştır. Bilişim teknolojilerindeki hızlı gelişim eğitim kurumlarının yeni teknolojilere uyum sağlamasını zorunlu hale getirmiştir. Ayrıca eğitim-öğretim faaliyetleri ile ilgili araştırmaların merkezinde, kalıcı ve üst düzey öğrenme becerisi kazandıracak uygulamalar yer almaktadır. Öğretimin etkililiği, öğrenenlerin öğretim faaliyetlerine katılımının (Şaban ve Şeker, 2010; Sarıtepeci, 2012; Durak, 2014) ve öğrenilenlerin kalıcılığının (Canbay, 2012; Kert ve Tektal, 2010) sağlandığı ölçüde artmaktadır. Bunu sağlamanın en kolay ve etkili yolu ise bilişim teknolojilerinin işe koşulmasıdır. Günümüzde bilişim teknolojilerinin eğitime entegrasyonu konusunda en kapsamlı gelişme "Bilgisayar Destekli Öğretim" (BDÖ) sistemleridir. Bilgisayar destekli öğretim, "bilgisayarın öğrenmenin meydana geldiği bir ortam olarak kullanıldığı, öğretim sürecini ve öğrenci motivasyonunu güçlendiren, öğrencinin kendi öğrenme hızına göre yararlanabileceği ve kendi kendine öğrenme ilkesinin bilgisayar teknolojisi ile birleşmesinden oluşmuş bir öğretim yöntemidir" (Şahin ve Yıldıım, 1999). Diğer bir tanıma göre de BDÖ, ders içeriklerinin ve öğretim faaliyetlerinin bilgisayar yoluyla aktarılmasıdır (Engin, Tösten ve Kaya, 2010). Öğrencinin motivasyonunu artırmayı hedefleyen BDÖ’de, bilgisayar, öğretmene yardımcı bir araç olarak kullanılmaktadır. Bir başka ifade ile BDÖ öğretmenin rehber, bilgisayarın ise öğrenme ortamı olarak kullanıldığı bir öğretim yöntemidir.

BDÖ, bir eğitsel ortam olarak, bilgisayarın öğretme-öğrenme süreçlerinde; öğretmenin eğitsel ortamı hazırlaması, öğrencilerinin yeteneklerini tanıması, onların yeteneklerine uygun bireyselleştirme, yönlendirme, alıştırma ve tekrar gibi etkinlikleri gerçekleştirmesi; öğreteceği konunun yapısına, belirlediği öğretim amaçlarına göre bilgisayarı değişik yer, zaman ve şekillerde kullanmasını gerekli kılmaktadır (Öğüt, Altun, Sulak ve Koçer, 2004).

BDÖ'in, Tarih öğretiminde, öğrencilere ilgi ve merak duygusu kazandırarak motivasyonlarını artırma, anlaşılması ve hatırlanması zor olan soyut kavramları model ve benzetim yolu ile somutlaştırma, çoklu ortam teknikleri (ses, animasyon, video, resim vb.) ile öğretimi daha etkili ve zevkli hale getirme gibi özellikleri bulunmaktadır. BDÖ sayesinde, eğitim-öğretim bireyselleştirilebilir ve öğretmen merkezli öğretimden öğrenci merkezli öğretime geçiş sağlanabilir. Böylece öğrencilerin, tarih konularını ve kavramlarını daha kolay anlamaları ve tarihe karşı olumlu tutum sergilemeleri sağlanabilir (Güven ve Sülün, 2012). BDÖ, öğrencilerin derse odaklanma süresini ve video, slayt, animasyon gibi çoklu ortam materyalleri ile derse olan ilgisini artırarak konunun anlaşılmasına büyük katkı sağlar. Öte yandan Ergin (1995) BDÖ ile ilgili yapılan araştırmalardan, BDÖ'in geleneksel öğretime kıyasla başarıyı \%1018 oranında artırdığı sonucuna ulaşmıştır. Bu konuda yapılan meta analizi sonuçları da bilgisayarların öğretimi olumlu yönde etkilediğini göstermektedir (Stites, 2003'den aktaran Altun, 2005).

BDÖ konusunda, araştırmacılar en çok geliştirilen modelin başarıya ve tutuma olan etkisini araştırmışlardır. Alanyazında BDÖ uygulamasının akademik başarıyı ve tutumu olumlu yönde etkilediğine dair çok sayıda araştırma vardır (Kılıç, Karadeniz ve Karataş, 2003; Usta, Bozdoğan ve Yıldırım, 2007; Yağcı, 2012; Yorgancı, 2014). Yüze yüze öğretim ile web destekli öğretimin başarı ve motivasyona etkisini araştıran Caldwell (2006), web destekli öğretimin yüz yüze öğretim kadar etkili olduğu sonucunu bulmuştur (Horzum ve Çakır Balta, 2008). Benzer şekilde Karadeniz ve Akpınar, (2015) 6. Sınıf “Madde ve Isı" ünitesine, Kırıkkaya, Dağ, Durdu ve Gerdan, (2016) 8. sınıf "Doğal Süreçler" ünitesine yönelik geliştirdiği Web Tabanlı Öğretim (WTÖ) materyalinin öğrencilerin başarılarına olumlu yönde katkı sağladığı sonucunu bulmuştur. Horzum ve Çakır Balta (2008) ise WTÖ'de farklı öğretim yöntemlerinin etkisini incelemiştir. Sonuç olarak karma öğrenme ortamında, öğrencilerin daha başarılı olduğunu bulmuştur. Ayrıca 
Çetin, Çalışkan ve Menzi (2012), akademisyenlerin web tabanlı öğretimi faydalı bulduklarını ve çeşitli boyutları ile araştırılması gerektiğini düşündüklerini ifade etmiştir. Farklı bir açıdan Kocaman ve Kızılkaya Cumaoğlu (2014) ingilizce kelime öğretiminde eğitsel yazılımların etkisini araştırmıştır. Sonuç olarak BDÖ'in kelime öğrenimi üzerinde olumlu etkileri olduğu sonucuna ulaşmıştır. Öte yandan Baltacı ve Akpınar (2011) öğrencilerin üstbiliş farkındalık düzeyine, WTÖ'in etkisinin olmadığı sonucuna ulaşmıştır.

Alanyazından BDÖ'in akademik başarı, motivasyon ve bireysel farklılık gibi çeşitli değişkenlere etkisini araştıran çok sayıda çalışma olduğu görülmektedir. Ancak öğrenilenlerin kalıcılığına etkisi üzerinde ve Tarih dersinin öğretiminde sınırlı sayıda çalışmaya rastlanmıştır. Bilgisayar destekli öğretimde, görsel ve işitsel materyaller, öğrenilenlerin kalıcılığında çok önemli rol oynamaktadır. Çünkü bilgisayar programları yardımı ile soyut kavramları somutlaştırmak çok kolaydır. Ayrıca geliştirilen materyal gelişen teknoloji ve değişen ihtiyaçlara göre rahatça güncelenebilmektedir. Buradan hareketle öğrenilenlerin kalıcılığının incelenmesi ve bu konuda yeni çalışmaların önerilmesi (Edrich vd., 2016; Maier, Wolf ve Randler, 2016) nedeniyle yapılan bu çalışmanın önemli olduğu düşünülmektedir. Bu bağlamda araştırmanın amacı; 10. sınıf Tarih dersinin, BDÖ yöntemiyle işlenmesinin, öğrencilerin akademik başarıları, öğrenilenlerin kalıcılı̆̆ı ve bilgisayara karşı tutumlarına etkisi olarak belirlenmiştir. Bu bağlamda aşağıdaki sorulara cevap aranmıştır.

1. BDÖ'in uygulandığı deney grubu öğrencileri ile geleneksel öğretim metotlarının uygulandığı kontrol grubu öğrencilerinin tarih dersine ilişkin akademik başarı puanları arasında anlamlı farklılık var mıdır?

a) Uygulama öncesi ve sonrasında öğrencilerin akademik başarı puanları arasında anlamlı farklılık var mıdır?

b) BDÖ’e yönelik uygulama öncesi akademik başarı puanları kontrol edildiğinde uygulama sonrasındaki başarı puanları gruba (Deney/Kontrol) göre anlamlı farklılık göstermekte midir?

c) BDÖ’e yönelik uygulama öncesi akademik başarı puanları kontrol edildiğinde uygulama sonrasında beş haftalık aradan sonraki başarı puanları gruba (Deney/Kontrol) göre anlamlı bir farklılık göstermekte midir?

2. Deney ve Kontrol grubu öğrencilerinin bilgisayara karşı tutum puanları arasında anlamlı bir farklılık var mıdır?.

a) Öğrencilerin uygulama öncesi ve sonrasında, bilgisayara karşı tutum puanları arasında anlamlı farklılık var mıdır?

b) BDÖ’e yönelik uygulama öncesi tutum puanları kontrol edildiğinde uygulama sonrasındaki tutum puanları gruba (Deney/Kontrol) göre anlamlı farklılık göstermekte midir?

\subsection{Araştırmanın Sınırlılıkları}

Araştırma, örneklem grubunu oluşturan 60 (28 Deney, 32 Kontrol) 10. sınıf öğrencisi, Illköğretim 10. sınıf Tarih dersi öğrenme alanı ve Ankara ili Yenimahalle ilçesindeki özel bir ortaöğretim okulu ile sınırlıdır. 


\section{YÖNTEM}

\subsection{Araştırmanın Modeli}

Bu araştırmada öntest - sontest kontrol gruplu yarı deneysel desen kullanılmıştır. Deneme modeli, doğrudan araştırmacının kontrolü altında, gözlenmek istenen verilerin araştırılarak neden-sonuç ilişkilerinin belirlendiği modeldir (Karasar, 2009).

\section{2. Çalışma Grubu}

Bu araştırma 2015-2016 Bahar döneminde Ankara'nın Yenimahalle ilçesindeki özel bir ortaöğretim okulunun 10. sınıfına devam eden ve Tarih dersini alan toplam 60 öğrenciyle yürütülmüştür.

Tablo 1

Çalışma Grubuna iliş̧kin Demografik Bilgiler

\begin{tabular}{lll}
\hline Cinsiyet & Deney Grubu & Kontrol Grubu \\
\hline Kız & 16 & 17 \\
Erkek & 12 & 15 \\
Toplam Öğrenci Sayısı & 28 & 32 \\
\hline
\end{tabular}

Tablo 1 incelendiğinde öğrencilerin 27'sinin erkek, 33'ünün kız olduğu görülmektedir. Deney grubunda 28 , kontrol grubunda ise 32 öğrenci bulunmaktadır.

\subsection{Uygulama}

Kontrol grubu, ders kitabından ve öğretmenin uyguladığı öğretim yöntem ve tekniklerinden yararlanmıştır. Bilgisayar destekli öğretimin uygulandığı deney grubuna ise, ilgili üniteyi kapsayan video, animasyon, slaytlar ve bilgisayar tabanlı testler uygulanmıştır. Deney ve kontrol grupları, ders kitabından ve öğretmenin uyguladığı öğretim yöntem ve tekniklerinden aynen yararlanmıştır. Bilgisayar destekli öğretimin uygulandığı deney grubuna fazladan, ilgili üniteyi kapsayan video, animasyon, slaytlar ve testler verilmiştir. Deney ve kontrol gruplarının araştırma değişkenleri ve önbilgiler açısından denk olup olmadığının belirlenmesi amacıyla her iki gruba akademik başarı ve bilgisayara yönelik tutum ölçeği uygulanmıştır. Sürecin sonunda öğrencilere daha önce uygulanmış olan akademik başarı testi ve tutum ölçeği sontest olarak tekrar uygulanmıştır.

\subsection{Veri Toplama Araçları}

\section{Akademik Başarı Testi}

10. sınıf Tarih dersi ile ilgili öğrencilerin ön bilgilerini ve uygulama sonunda başarı düzeylerini ölçmek amacıyla 25 maddeden oluşan başarı testi hazırlanmıştır. Hazırlanan bu sorular beş alan uzmanının görüşüne sunulmuştur. Öğretmenlerin görüşü doğrultusunda 20 soruluk çoktan seçmeli başarı testi geliştirilmiştir.

Hazırlanan 20 soruluk başarı testi öğrencilere öntest ve sontest olarak uygulanmıştır. Her doğru cevaba " 1 " puan, yanlış ya da boş cevaba "0" puan verilmiştir. Bu puanlama sonucunda testten alınabilecek en yüksek puan " 20 " en düşük puan ise " 0 " olarak hesaplanmıştır.

\section{Bilgisayara Karşı Tutum ölçeği}

Veri toplama aracı olarak 12-18 yaş arası öğrencilerin derslerinde bilgi teknolojilerinden yararlanma düzeylerini belirlemek amacıyla Demir ve Yurdugül (2014) tarafından Türkçeye uyarlanan 20 madde ve üç faktörden oluşan beş'li likert tipi “Ortaokul ve 
Lise Öğrencileri için Bilgisayara Yönelik Tutum (BYT) Ölçeği” kullanılmıştır. Ölçeğin geliştirilmesinde, veriler Ankara'daki çeşitli ortaöğretim ve lise kademesinde öğrenim gören 1678 öğrenciden elde edilmiştir. Ölçeğin geçerlik çalışması hem açıklayııı faktör analizi hem de doğrulayıcı faktör analizi hesaplamaları ile gerçekleştirilmiştir. Ölçek, bilgisayardan hoşlanma (1..6), bilgisayarın önemi (7..12) ve bilgisayar kaygısı (13..20) alt boyutlarından oluşmaktadır. Ölçeğin alt boyutlarına ilişkin iç tutarlık katsayıları .75 ve .81 arasında değerler almaktadır. Tüm ölçek için iç tutarlık katsayısı (Cronbach Alpha) ise .83 olarak hesaplanmıştır. Ölçekteki her bir madde için "Kesinlikle katılmıyorum", "Katılmıyorum", "Fikrim yok", "Katılıyorum" ve "Kesinlikle katılıyorum" seçenekleri kullanılmıştır.

\section{Kalıcılık Testi}

Araştırmacı tarafından, öğrenilenlerin kalıcılığını ölçmek amacıyla uzman görüşleri alınarak sekiz açık uçlu soru geliştirilmiştir. Il|gili konunun sunumundan beş hafta sonra öğrencilere hazırlanan kalıcılık testi uygulanmıştır. Her doğru cevaba 5 , yanlış cevaba ise 0 puan verilmiştir. Bu puanlama sonucunda testten alınabiliecek en yüksek 40 , en düşük puan ise 0 'dır.

\subsection{Verilerin Çözümlenmesi ve Yorumlanması}

Verilerin analizine başlamadan önce verilerin normallik testleri kapsamında her bir bağımlı değişkenin normal dağılım gösterip-göstermediğini ölçmek için Kolmogorov-Smirnov normalite testi sonuçlarına bakılmıştır. Kolmogorov-Smirnov normallik testi analiz sonuçları, bağımlı değişkenler için tüm gruplarda normal dağılım gösterdiğinden parametrik testler kullanılmıştır. Öğrencilerin bilgisayara yönelik tutumlarının ve akademik başarı puanlarının belirlenmesinde betimsel istatistikler olarak frekans (f), yüzde (\%), ortalama ( $\bar{X}$ ) ve standart sapma (ss) değerleri kullanılmıştır. Tutum ölçeğindeki maddeler "1- Kesinlikle katılmıyorum", "2- Katılmıyorum", "3-Fikrim yok", "4-Katılıyorum" ve "5- Kesinlikle katılıyorum" şeklinde puanlandırılmıştır. Ölçekteki ters maddeler için ise tam tersi puanlama yapılmıştır. Ölçekten en az 20 en yüksek 100 puan alınabilir. Ölçekten alınan yüksek puan öğrencinin bilgisayara yönelik tutumunun yüksek olduğu anlamına gelir.

\subsection{BULGULAR}

\subsection{Birinci Alt Probleme Ait Bulgular}

Aşağıda birinci alt problemi “BDÖ'in uygulandığı deney grubu öğrencileri ile geleneksel öğretim metotlarının uygulandığı kontrol grubu öğrencilerinin tarih dersine ilişkin akademik başarı puanları arasında anlamlı farklılık var mıdır" şeklinde belirlenmiştir. Aşağıda birinci alt probleme yönelik bulgular yer almaktadır.

Tablo 2

Akademik Başarı Öntest, Sontest ve Kalıcılık Testi Ortalama Puanları

\begin{tabular}{lcccccccc}
\hline Grup & \multicolumn{3}{c}{ Öntest } & \multicolumn{3}{c}{ Sontest } & \multicolumn{2}{c}{ Kalıcılık Testi } \\
\hline & $\mathrm{N}$ & $\bar{X}$ & $\mathrm{~s}$ & $\bar{X}$ & $\mathrm{~s}$ & $\bar{X}$ & $\mathrm{~s}$ \\
Deney Grubu & 28 & 5,53 & 2,57 & 16,14 & 2,86 & 12,89 & 5,01 \\
Kontrol Grubu & 32 & 5,81 & 1,85 & 12,93 & 3,06 & 8,37 & 4,59 \\
\hline
\end{tabular}

Tablo 2 incelendiğinde uygulama öncesinde deney grubunun öntest puan ortalaması $(\bar{X}=5.53)$ ile kontrol grubunun öntest puan ortalaması $(\bar{X}=5.81)$ arasındaki farkın anlamlı olmadığı görülmektedir (p>.05). Uygulama sonrasında sontest ortalama puanları karşılaştırıldığında ise deney grubu lehine anlamlı farklılı̆ın olduğu görülmektedir ( $p<.05)$.

Tablo 3'de deney ve kontrol grubu öğrencilerinin sontest ve önteste göre düzeltilmiş sontest ortalama puanları yer almaktadır. 
Tablo 3

Sontest Başarı Puanlarının Gruba Göre Betimsel Istatistikleri

\begin{tabular}{llll}
\hline & N & Ortalama & Düzeltilmiş Ortalama \\
\hline Deney Grubu & 28 & 16,14 & 16,20 \\
Kontrol Grubu & 32 & 12,93 & 12,89 \\
\hline
\end{tabular}

Tablo 4'de deney grubu öğrencilerinin önteste göre düzeltilmiş sontest ortalama puanlarının $(\bar{X}=16.20)$ kontrol grubu öğrencilerinin ise $(\bar{X}=12.89)$ olduğu görülmektedir. Aradaki farkın anlamlı olup olmadığını belirlemek için yapılan Ancova testi analiz sonuçları ise Tablo 4'de verilmiştir.

Kovaryans analizinin geçerli olabilmesi için varyansların homojenliği testi yapılmalıdır. Levene's Test sonucuna göre $p$ değeri .241 olarak hesaplanmıştır, bu değer .05'ten büyük olduğu için varyansların homojenliği varsayımı sağlanmıştır. Bağımlı değişken (Sontest) ile kodeğişken (Öntest) eğiminin yaklaşık aynı olup olmadığını anlamak için yapılan test sonucuna göre $p$ değeri .293 olarak hesaplanmıştır, bu değer .05 'ten büyük olduğundan “iki grup için eğim aynıdır" hipotezi de sağlanmıştır.

Tablo 4

Öntest Başarı Puanlarına Göre Düzeltilmiş Sontest Başarı Puanlarının Gruba Göre ANCOVA Sonuçları

\begin{tabular}{llllll}
\hline Varyansın Kaynağı & $\begin{array}{l}\text { Kareler } \\
\text { Toplamı }\end{array}$ & sd & $\begin{array}{l}\text { Kareler } \\
\text { Ortalaması }\end{array}$ & $\mathbf{F}$ & $\mathbf{p}$ \\
\hline Öntest (Reg.) & 37,46 & 1 & 37,46 & 4,48 &, 039 \\
Grup & 162,52 & 1 & 162,52 & 19,47 &, 000 \\
Hata & 475,84 & 57 & 8,34 & & \\
Toplam & 13166,00 & 59 & & & \\
\hline
\end{tabular}

Tek faktörlü kovaryans analizi (ANCOVA) sonuçlarına göre, grupların uygulama öncesi başarı öntest puanlarına göre düzeltilmiş başarı sontest puanları arasında anlamlı farklılık bulunmaktadır $\left(F_{[1-57]}=19.47, p<0.01\right)$.

Tablo 5'de deney ve kontrol grubu öğrencilerinin kalıclık testi ve önteste göre düzeltilmiş kalıcılık testi ortalama puanları yer almaktadır.

Tablo5

Kalıcık ve Önteste Göre Düzeltilmiş Kalıcılık Testi Ortalama Puanları

\begin{tabular}{llll}
\hline & N & Ortalama & Düzeltilmiş Ortalama \\
\hline Deney Grubu & 28 & 12,89 & 12,89 \\
Kontrol Grubu & 32 & 8,37 & 8,38 \\
\hline
\end{tabular}

Tablo 5'de deney grubu öğrencilerinin önteste göre düzeltilmiş kalıcılık testi ortalama puanlarının $(\bar{X}=12.89)$ kontrol grubu öğrencilerinin ise $(\bar{X}=8.37)$ olduğu görülmektedir. Aradaki farkın anlamlı olup olmadığını belirlemek için yapılan Ancova testi analiz sonuçları ise Tablo 6'da verilmiştir.

Varyansların homojenliğini hesaplamak için yapılan Levene's Testi sonucuna göre $p$ değeri .658 olarak hesaplanmıştır, bu değer .05'ten büyük olduğu için varyansların homojenliği varsayımı sağlanmıştır. Bağımlı değişken (Sontest) ile kodeğişken (Öntest) eğiminin yaklaşık aynı olup olmadığını anlamak için yapılan test sonucuna göre $p$ değeri 0517 olarak 
Tarih Öğretiminde Bilgisayar Destekli Öğretimin Akademik Başarıya, Öğrenilenlerin Kalıcılı̆ına ve Bilgisayara Karşı Tutuma Etkisi

hesaplanmıştır, bu değer .05'ten büyük olduğundan "iki grup için eğim aynıdır" hipotezi de sağlanmıştır.

Tablo 6

Öntest Başarı Puanlarına Göre Düzeltilmiş Kalıcılık Başarı Testi Puanlarının Gruba Göre ANCOVA Sonuçları

\begin{tabular}{llllll}
\hline Varyansın Kaynağı & $\begin{array}{l}\text { Kareler } \\
\text { Toplamı }\end{array}$ & sd & $\begin{array}{l}\text { Kareler } \\
\text { Ortalaması }\end{array}$ & $\mathbf{F}$ & $\mathbf{p}$ \\
\hline Öntest (Reg.) & 178 & 1 &, 178 &, 008 &, 931 \\
Grup & 302,66 & 1 & 302,66 & 12,95 &, 001 \\
Hata & 1332,00 & 57 & 23,36 & & \\
Toplam & 8231,00 & 59 & & & \\
\hline
\end{tabular}

Tek faktörlü kovaryans analizi (ANCOVA) sonuçlarına göre, grupların uygulama öncesi başarı öntest puanlarına göre düzeltilmiş akademik başarı kalıcılık testi puanları arasında anlamlı farklılık vardır $\left(F_{[1-57]}=12.95, p<0.05\right)$.

\section{2. İkinci Alt Probleme Ait Bulgular}

Öğrencilerin uygulama öncesinde yapılan Bilgisayara Yönelik Tutum öntest, sontest ortalama puanları Tablo 7' de verilmiştir.

Tablo 7

Bilgisayara Karşı Tutum Öntest ve Sontest Ortalama Puanları

\begin{tabular}{lccccc}
\hline Grup & \multicolumn{3}{c}{ Öntest } & \multicolumn{3}{c}{ Sontest } \\
\hline & N & $\bar{X}$ & $\mathrm{~s}$ & $\bar{X}$ & $\mathrm{~s}$ \\
Deney Grubu & 28 & 62,6429 & 10,63960 & 61,5000 & 10,50749 \\
Kontrol Grubu & 32 & 58,7187 & 12,75130 & 58,7813 & 11,29583 \\
\hline
\end{tabular}

Tablo 7'de deney grubu öğrencilerinin tutum öntest ortalama puanlarının $(\bar{X}=62.64)$, sontest ortalama puanlarının $\overline{(X}=61.50)$, kontrol grubu öğrencilerinin öntest ortalama puanlarının $(\bar{X}=58.72)$, sontest ortalama puanlarının ise $(\bar{X}=58.78)$ olduğu görülmektedir.

Tablo 8'de deney ve kontrol grubu öğrencilerinin sontest ve önteste göre düzeltilmiş sontest ortalama puanları yer almaktadır.

Tablo 8

BYT Sontest ve Önteste Göre Düzeltilmiş Sontest Ortalama Puanları

\begin{tabular}{llll} 
& N & Ortalama & Düzeltilmiş Ortalama \\
\hline Deney Grubu & 28 & 61,50 & 61,38 \\
Kontrol Grubu & 32 & 58,78 & 58,88 \\
\hline
\end{tabular}

Tablo 8'de deney grubu öğrencilerinin önteste göre düzeltilmiş sontest ortalama puanlarının $(\bar{X}=61.38)$ kontrol grubu öğrencilerinin ise $(\bar{X}=58.88)$ olduğu görülmektedir. Aradaki farkın anlamlı olup olmadığını belirlemek için yapılan Ancova testi analiz sonuçları ise Tablo 9'da verilmiştir.

Varyansların homojenliğini hesaplamak için yapılan Levene's Testi sonucuna göre $p$ değeri .614 olarak hesaplanmıştır, bu değer .05'ten büyük olduğu için varyansların homojenliği varsayımı sağlanmıştır. Bağımlı değişken (Sontest) ile kodeğişken (Öntest) eğiminin yaklaşık aynı olup olmadığını anlamak için yapılan test sonucuna göre p değeri .058 olarak 
hesaplanmıştır, bu değer .05 'ten büyük olduğundan "iki grup için eğim aynıdır" hipotezi de sağlanmıştır.

Tablo 9

BYT Öntest Puanlarına Göre Düzeltilmiş Sontest Puanlarının Gruba Göre ANCOVA Sonuçları

\begin{tabular}{llllll}
\hline Varyansın Kaynağı & $\begin{array}{l}\text { Kareler } \\
\text { Toplamı }\end{array}$ & sd & $\begin{array}{l}\text { Kareler } \\
\text { Ortalaması }\end{array}$ & F & p \\
\hline Öntest (Reg.) & 25,57 & 1 & 25,57 &, 21 &, 648 \\
Grup & 90,62 & 1 & 90,62 &, 75 &, 391 \\
Hata & 6910,89 & 57 & 121,24 & & \\
Toplam & 223407,00 & 59 & & & \\
\hline
\end{tabular}

Tek faktörlü kovaryans analizi (ANCOVA) sonuçlarına göre, grupların uygulama öncesi BYT öntest puanlarına göre düzeltilmiş sontest puanları arasında anlamlı bir fark bulunmamaktadır $\left(F_{[1-57]}=.75,>0.05\right)$.

\section{SONUÇ ve TARTIŞMA}

Araştırma sonucunda, BDÖ'in uygulandığı deney grubu öğrencilerinin tarih dersi başarı sontest puanları ile geleneksel öğretim metotlarının uygulandığı kontrol grubu öğrencilerinin başarı sontest puanları arasında deney grubunun lehinde anlamlı farklılık olduğu görülmüştür. Bununla birlikte uygulama sonrasında kontrol grubunun sontest akademik başarı puanında da artış olduğu gözlenmiştir. Bu sonuç, BDÖ'in öğrencilerin akademik başarılarını olumlu yönde etkilediğini göstermektedir. Bunun nedeni olarak, öğretmenin konuyu işlerken gerekli durumlarda bilgisayarı yardımc bir araç olarak kullanarak soyut kavramları daha somut hale getirmesi gösterilebilir. Bunun yanı sıra, öğretimsel içerikle ilgili alıştırma ve uygulamaların aktarılmasında, görsel ve işitsel materyallerin kullanımı hedef kazanımlara ulaşmada olumlu katkı sağlamaktadır. Bu sonuç literatürü destekler niteliktedir. Güven ve Sülün (2012) BDÖ'in çoklu ortam araçlarının kullanılması sayesinde konuyu somutlaştırdığını dolayısıyla öğrencinin algılamasını kolaylaştırdığını ifade etmiştir. Karadeniz ve Akpınar (2015), web tabanlı öğretimin öğrencilerin başarılarına olumlu etki yaptığı sonucunu bulmuştur. Alanyazın tarandığında; neredeyse tüm çalışmalarda web tabanlı öğretimin öğrencilerin akademik başarılarına katkı sağladığı sonucu bulunmuştur (Baturay, Yıldııı ve Daloğlu, 2009; Berigel, 2007; Özkan, 2010; Serin, 2011; Yen, Tuan ve Liao, 2010).

Diğer araştırma sonucu, deney grubu öğrencilerinin kalıcılık testi ortalama puanları ile kontrol grubu öğrencilerinin kalıcılık testi ortalama puanları arasında deney grubunun lehine anlamlı farklılığın olduğudur. Bu sonuca göre; bilgisayar destekli öğretimin öğrenilenlerin kalıcılığına olumlu katkı sağladığı söylenebilir. Benzer şekilde Çetin, Çalışkan ve Menzi'nin (2013). çalışmasında da öğrenmenin kalıcılığında bilgisayar destekli öğretimin katkısı olduğu sonucu bulunmuştur

Araştırmanın diğer bir sonucu ise; deney ve kontrol grubu öğrencilerinin bilgisayara yönelik tutumları arasında anlamlı farklılığın olmadığıdır. Deney grubu ve kontrol grubu arasında bilgisayara yönelik tutumda anlamlı farklılı̆ın olmaması; bu yöntemin daha önce uygulanmamış olması ve 10 hafta gibi kısa bir sürede bitmesi gösterilebilir. Ayrıca tutum ve davranış gibi kişisel özellikler zor değişen özelliklerdir. Bu sonuç literatür ile büyük oranda farklılık göstermektedir. Örneğin Aslan, Kırbağ Zengin ve Kırılmazkaya (2015) bilgisayar destekli öğretimin öğretmen adaylarının bilgisayarın bilimsel kullanımına yönelik tutumlarına olumlu yönde katkı sağladığı sonucunu bulmuştur. Alkan ve Koçak'da (2015) BDÖ'in öğrencilerin eğitim teknolojileri kullanımına yönelik olumlu tutumlarını artırdığı sonucunu bulmuştur. 
Özetle, bu çalışma ile; bilgisayar destekli öğretimin, akademik başarıyı ve öğrenilenlerin kalıcılığını artırdığı belirlenmiştir. Deneysel işlem öğrencilerin bilgisayara yönelik tutumlarını etkilememiştir. Buradan hareketle, öğretimsel içeriği uygun olan derslerin anlatımında BDÖ’in yapılması önerilmektedir. Bunun içinde öğretmen adaylarına, ders içeriklerini bilgisayar ortamında geliştirmelerini sağlayacak araçların kullanımı ile ilgili eğitimin verilmesi önerilmektedir. Aynı zamanda, eğitimcilerin ihtiyaç duydukları güncel çoklu ortam öğrenme materyallerinin geliştirilmesi ve daha önce geliştirilen materyallere ulaşım olanaklarının arttırılması önemli görülmektedir. Bunun dışında en az bir dönemi kapsayacak bir uygulamanın öğrencilerin bilgisayara yönelik tutumlarına olumlu katkı sağlayacağı düşünülmektedir.

\section{KAYNAKLAR}

Altun, A. (2005). Gelişen teknolojiler ve yeni okuryazarlıklar. Ankara: Anı Yayıncılık.

Alkan, F., \& Koçak, C. (2015). Chemistry laboratory applications supported with simulation. Procedia-Social and Behavioral Sciences, 176, 970-976.

Aslan, S., Kırbağ Zengin, F., \& Kırılmazkaya, G. (2015). Bilgisayar destekli öğretimin fen bilgisi öğretmen adaylarının tutum ve akademik başarılarına etkisi. Journal of International Social Research, 8(37).

Baltacı, M., \& Akpınar, B. (2011). Web tabanlı öğretimin öğrenenlerin üstbiliş farkındalık düzeyine etkisi. Mustafa Kemal Üniversitesi Sosyal Bilimler Enstitüsü Dergisi, 8(16), 319333.

Baturay, M., Yıldırım, S., ve Daloğlu, A. (2009). Effects of web-based spaced repetition on vocabulary retention of foreign language learners. Eurasian Journal of Educational Research (EJER), 8(34), 17-36.

Berigel, M. (2007). Web tabanlı ingilizce öğretim materyalinin tasarımı, uygulanması ve değerlendirilmesi. (Yayımlanmamış Yüksek Lisans Tezi). Karadeniz Teknik Üniversitesi, Fen Bilimleri Enstitüsü, Trabzon, Türkiye.

Caldwell, E.R. (2006). A comparative study of three instructional modalities in a computerprogramming course: traditional instruction, web based instruction, and online instruction. (Unpublished PDH Thesis). The University of North Carolina at Greensboro. USA.

Canbay, ì. (2012). Matematikte eğitsel oyunların 7.sınıf öğrencilerinin öz düzenleyici öğrenme stratejileri ,motivasyonel inançları ve akademik başarılarına etkisinin incelenmesi. Yüksek Lisans Tezi, Marmara Üniversitesi, Eğitim Bilimleri Enstitüsü İlköğretim Anabilim Dalı Ilköğretim Matematik Öğretmenliği Bilim Dalı ,istanbul.

Çetin, O., Çalışkan, E., \& Menzi, N. (2012). Öğretmen adaylarının teknoloji yeterlilikleri ile teknolojiye yönelik tutumları arasındaki ilişki. ilköğretim Online, 11(2), 273-291.

Çetin, O., Çalışkan, E., \& Menzi, N. (2013). Web tabanlı öğretime yönelik akademisyen görüşleri. Elementary Education Online, 12(3), 886-902.

Demir, Ö., \& Yurdugül, H. (2014). Ortaokul ve lise öğrencileri için bilgisayara yönelik tutum ölçeğinin türkçe'ye uyarlanması. Eğitim ve Bilim, 39(176), 247-256. http://doi.org/10.15390/EB.2014.3619.

Durak, G. (2014). The Effects Of A Distance Education Programming Language Course On Student Performance. Eğitimde Kuram ve Uygulama, 10(1), 202-219. 
Edrich, T., Stopfkuchen-Evans, M., Scheiermann, P., Heim, M., Chan, W., Stone, M. B., \& Szabo, A. L. (2016). A comparison of web-based with traditional classroom-based training of lung ultrasound for the exclusion of pneumothorax. Anesthesia and Analgesia, 123(1), 123-128.

Engin, A.O., Tösten, R., ve Kaya, M.D. (2010). Bilgisayar Destekli Eğitim. Sosyal Bilimler Enstitüsü Dergisi, 5, 69-80.

Ergin, A. (1995). Öğretim teknolojisi. Ankara: PegemA Yayınları.

Güven, G., \& Sülün, Y. (2012). Bilgisayar destekli öğretimin 8. sınıf fen ve teknoloji dersindeki akademik başarıya ve öğrencilerin derse karşı tutumlarına etkisi. Türk Fen Eğitimi Dergisi, 9(1), 68-79.

Horzum, M. B., \& Çakır Balta, Ö. (2008). Farklı web tabanlı öğretim ortamlarında öğrencilerin başarı ,motivasyon ve bilgisayar kaygı düzeyleri. Hacettepe Üniversitesi Eğitim Fakültesi Dergisi, 34, 140-154.

Karadeniz, A., \& Akpınar, E. (2015). Web Tabanlı Öğretimin İlköğretim Öğrencilerinin Akademik Başarılarına Etkisi. Egitim ve Bilim, 40(177), 217-231. http://doi.org/10.15390/EB.2015.2702.

Kılıç, E., Karadeniz, Ş., \& Karataş, S. (2003). İnternet destekli yapıcı öğrenme ortamları. Gazi Üniversitesi Gazi Eğitim Fakültesi Dergisi, 23(2).

Karasar, N. (2009). Bilimsel araştırma yöntemi (20. baskı). Ankara: Nobel Yayıncılık.

Kırıkkaya, E. B., Dağ, F., Durdu, L., \& Gerdan, S. (2016). 8 . Sınıf doğal süreçler ünitesi için hazırlanan bdö yazılımı ve akademik başarıya etkisi. Ilköğretim Online, 15(1), 234-250.

Kert, S.B. ve Tekdal, M. (2008). Alanyazındaki tasarım ilkelerine uygun olarak geliştirilmiş çoklu ortam ders yazılımının lise düzeyi fizik öğretiminde akademik başarıya ve kalıcılığa etkisi. Pamukkale Üniversitesi Eğitim Fakültesi Dergisi. 23 (1), 120-131.

Kocaman, O., \& Kizilkaya Cumaoğlu, G. (2014). The effect of educational software (denıs) and games on vocabulary learning strategies and achievement. Eğitim ve Bilim, 39(176), 305-316. http://doi.org/10.15390/EB.2014.3704.

Maier, U., Wolf, N., \& Randler, C. (2016). Effects of a computer-assisted formative assessment intervention based on multiple-tier diagnostic items and different feedback types. Computers \& Education, 95, 85-98.

Öğüt, H., Altun, A.A., Sulak, S.A. \& Koçer, H.E. (2004). Bilgisayar destekli, internet erişimli interaktif eğitim cd'si ile e-eğitim. The Turkish Online Journal of Educational Technology, 2(4).

Özkan, S. (2010). Illköğretim 7. sınıf fen ve teknoloji dersi için web tabanlı bir öğretim materyalinin geliştirilmesi. (Yayımlanmamış yüksek lisans tezi). Ondokuz Mayıs Üniversitesi Fen Bilimleri Enstitüsü, Samsun.

Sarıtepeci, M. (2012). Illköğretim 7. sınıf sosyal bilgiler dersinde harmanlanmış öğrenme ortamlarının öğrencilerin derse katılımına, akademik başarısına, derse karşı tutumuna ve motivasyonuna etkisi. Gazi Üniversitesi Eğitim Bilimleri Enstitüsü, Ankara.

Serin, O. (2011). The effects of the computer-based instruction on the achievement and problem solving skills of the science and technology students. The Turkish Online Journal of Educational Technology - TOJET, 10(1), 183-201. 
Şaban, A. i., \& Şeker, M. (2010). İlköğretim 5 sınıf öğrencilerinin performans görevlerindeki başarıları ile ailelerinin eğitim öğretim çalışmalarına katıım düzeyleri arasındaki ilişkinin belirlenmesi. Çukurova Üniversitesi Sosyal Bilimler Enstitüsü Dergisi, 19(3).

Şahin, T. ve Yıldırım, S. (1999), Öğretim teknolojileri ve materyal geliştirme. Ankara: Anı Yayıncilık.

Usta, E., Bozdoğan, A. E., \& Yıldırım, K. (2007). Sınıf öğretmeni adaylarının internet kullanımına ilişkin tutumlarının değerlendirilmesi. Ahi Evran Üniversitesi Kırşehir Eğitim Fakültesi Dergisi, 8(1).

Yağcı, M., Ekiz, H. ve Gelbal, S. (2012). Çevrimiçi sınav ortamlarının öğrencilerin akademik başarılarına etkisi. NWSA-Education Sciences, 7(1), 331-339.

Yen, H. C., Tuan, H. L. ve Liao, C. H. (2010). Investigating the influence of motivation on students' conceptual learning outcomes in web-based vs. classroom-based science teaching contexts. Research in Science Education, 41(1), 211-224.

Yorgancı, S. (2014). Web tabanlı uzaktan eğitim yönteminin öğrencilerin matematik başarılarına etkileri. K.Ü. Kastamonu Eğitim Dergisi, 23(3), 1401-1420. 


\section{SUMMARY}

Scientific and technological developments have influenced education as well as industry. Accordingly, information technology has been integrated with education systems. The great pace in developments experienced with information technologies required education institutions to new technologies. Hence, studies on education-teaching activities are oriented on applications which ensure learners to gain skills for persistent and high level of learning achievement. Computer Adided Teaching (CAT) in history teaching is distinguished with characteristics such as capture students' interest and curiosity, motivating them, concretization of abstract concepts difficult to comprehend or remember through relevant models and simulation, developing learning experience to make fun and entertaining through multimedia methods.

It could be seen in the relevant literature that there are numbers of studies focused on the effect of the CAT on different variables such as academic success, motivation and individual differences. However, limited study was found on its effect on persistency of learning and history teaching. In this sense, the objective of the present study is to determine the effect of instruction of history course to 10th graders by means of the CAT on their academic success levels, persistency of learning and their attitude towards computer.

In this study, semi-empirical research pattern with pre- and post-test and control groups was utilized. The study was conducted on totally 60 students receiving history course at the 10th grade in a private secondary school in Yenimahalle County of Ankara City in the academic period of 2015-2016.

Whereas the control group used regular course book and teaching method and technique employed by teacher, the experiment group utilized the CAT method studied the history course by means of video, animation, slides and computer based test covering the relevant curriculum. In order to determine whether experiment and control groups were equivalent in terms of study variables and preliminary information, both groups were applied academic success and computer attitude scale. As a result of the study, students were applied academic success test previously applied and attitude scale once again as a post-test.

Finally, a significant difference was determined between post-test academic success scores of the experiment group and the control group in the favor of the experiment group. Additionally, an increase was observed with the post test academic success scores of the experiment group at the end of the application. This result suggests that the CAT has positive effect on students' academic success levels.

Another finding was the significant difference between the mean scores of the experiment and control groups in persistence tests in the favor of the experiment group. Accordingly, it is possible to conclude that CAT has positive contribution into persistence of learning.

Additionally, no significant difference was determined between experiment and control groups in terms of their attitude towards computer. The fact that this method was applied for the first time and it was applied for a brief of time period like 10 weeks could be result of missing relationship between the control and experiment groups. Moreover, personal characteristics such as attitude and behavior are difficult to change.

In sum, this study determined that CAT has positive influence on academic success and persistence of learning. Experimental process was no effective on students' attitude towards computer. Conclusively, it is suggested that the CAT method could be harnessed in instruction of courses with appropriate content. To that end, it is suggested that it is necessary to provide training to prospect teachers concerning the tools which allow them to develop their course content for computer environment. In the meantime, it is considered that necessary multimedia learning materials need to be developed and previously developed materials must be made available and easily accessible for educators. Furthermore, an application which could cover at least one semester would make positive contribution into students' attitude towards computer. 